\title{
Exploring research hypotheses in green computing
}

\author{
Ikram Hamizi, Zamira Kholmatova, Giancarlo Succi \\ ${ }^{1}$ Institute of Software Development and Engineering, Innopolis University, Innopolis 420500, Russia.
}

Correspondence to: Prof. Giancarlo Succi, Institute of Software Development and Engineering, Innopolis University, Innopolis 420500, Russia. E-mail: g.succi@innopolis.ru

How to cite this article: Hamizi I, Kholmatova Z, Succi G. Exploring research hypotheses in green computing. J Smart Environ Green Comput 2021;1:120-30. http://dx.doi.org/10.20517/jsegc.2021.05

Received: 9 Mar 2021 First Decision: 26 May 2021 Revised: 13 Jun 2021 Accepted: 13 Jul 2021 Published: 29 Jul 2021

Academic Editor: Patricia Melin Copy Editor: Xin-Jun Chen Production Editor: Xin-Jun Chen

\begin{abstract}
This paper reviews the research work done in the last 11 years in the area of green computing and analyzes the associated hypotheses, which are then structured in taxonomy and explored to pave the way for a comprehensive view of future research in the area. With the help of the taxonomy, we can understand which of the problems needs more attention. For example, when there is a small number of studies related to a problem, research needs to be conducted on this topic, while a huge number of studies could raise contradictory results that can be aggregated to a unified answer with a meta-analysis. Among the hypotheses generated, one can choose to investigate the hypotheses with a sufficient number of papers.
\end{abstract}

Keywords: Research synthesis in software engineering, meta-analysis in software engineering, evidence-based software engineering

\section{INTRODUCTION}

The growth of energy consumption has become a vital problem affecting everyday life. The number of smartphone users is approximately 6378 million and the number of sold laptops exceeds 220 million. This technology impacts the environment through the production, use, and disposal of digital devices. In addition,

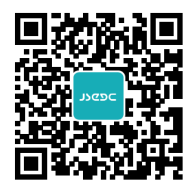


sophisticated users also want their smartphones and laptops to work longer between charging. Thus, it is important to find a way to reduce the energy consumed by such devices. One of the existing solutions is to reduce the energy consumed by the software running on them.

The problem of energy spent by different devices has turned into the problem of understanding how to develop applications that are "energy friendly", and this problem has already been partially addressed in the literature on the impact of development approaches ${ }^{[1,2]}$ and design choice ${ }^{[3]}$ on energy consumption. Many researchers have proposed tools and methods for estimating the energy spent by different devices ${ }^{[4-6]}$. Thanks to the investigation done in this area, developers can track the energy consumed by their software, find "code smells", and improve the efficiency of their products.

Due to the great variety of existing approaches, frameworks, and tools for developing applications, the problem of energy-efficient code can be explored from numerous perspectives. Now, we need to understand the current open questions in this area. To provide a novel approach, we decided to investigate the possible hypotheses that can be derived from the studies existing in the considered field. To do this, we firstly conducted a literature review in the area of energy consumption in software engineering. The literature review gave us a vision of the problem at the current moment. The awareness about the energy problem from the software side has already awakened, and the work on optimizing energy consumption is in progress ${ }^{[7,8]}$. The second step was to select studies with empirical results to define possible hypotheses. We found 13 papers about tools for estimation of energy consumption and 39 and 35 papers related to the impact of design choice and platform issues on energy consumption, respectively.

The basic dimensions of a problem led us to the formulation of the important questions ${ }^{[9]}$. In our case, these dimensions can be different devices, how energy consumption was measured, and the research topics addressed by the papers. Based on this information, we defined the following research questions:

$\mathrm{RQ}_{1}$ : What are the papers that addressed energy consumption in software engineering from 2010 to 2020 ?

$\mathrm{RQ}_{2}$ : For which devices was the energy consumption measured in the existing studies?

$\mathrm{RQ}_{3}$ : What hypotheses can we derive from the studies found?

With the help of such investigation, we can understand the current trends in "green" computing, namely which algorithms, methods, and techniques are the more efficient.

This work is organized as follows. The Review Protocol section presents the protocol followed to review the existing work. The Results section presents the results of the review. The Discussion section discusses the results found. The Conclusion section draws some conclusions.

\section{REVIEW PROTOCOL}

Our research was conducted based on a guideline for systematic reviews appropriate for software engineering researchers proposed by Kitchenham ${ }^{[10]}$. The search strategy for this investigation was defined by the research questions stated above.

To find relevant studies, we used a manual search with the Google Scholar engine since it includes most peerreviewed scientific journals and conference proceedings. We searched for all papers related to energy consumption in software development from 2010 to 2021 . The search strings were generated using the PICO approach $^{[11]}$. The number of papers found for each search query is presented in Table 1.

To be included for the further consideration, the paper should: 
Table 1. Search queries

\begin{tabular}{ll}
\hline Search query & Number of papers \\
\hline (energy OR power) (consumption OR efficiency) in software development & 74 \\
(energy OR power) (consumption OR efficiency) in (mobile devices OR & 129 \\
& \\
smartphones) & 70 \\
(energy OR power) (consumption OR efficiency) in (cloud systems) & 70 \\
(energy OR power) (consumption OR efficiency) in (embedded systems) & 67 \\
\hline
\end{tabular}

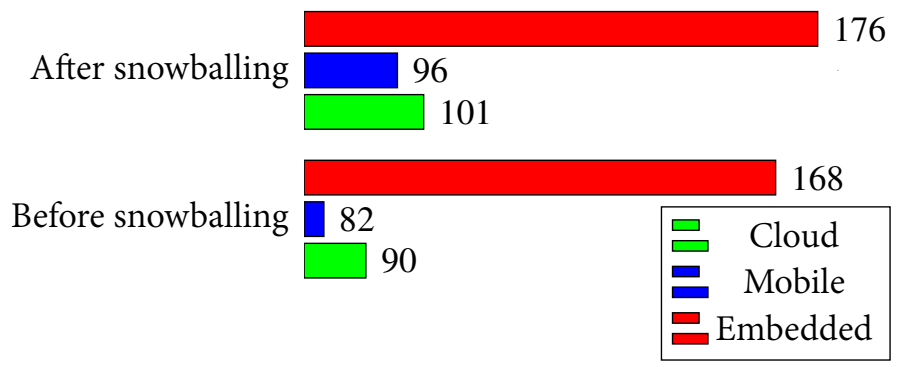

Figure 1. Comparison of the number of papers before and after applying the snowballing method.

- be peer-reviewed;

- be written in English; and

- contain information about energy consumption from the software perspective.

After quality assessment of studies based on the title, abstract, and keywords, we rejected $43.4 \%$ of papers. During the search process, we identified three big categories based on the devices for which the energy consumption was measured. These categories are mobile devices, embedded, and cloud systems.

However, after these steps, one should check the references in the already selected studies (backward snowballing) or check the studies in which the reference part contains the selected one (forward snowballing). We increased the number of papers found by using forward ${ }^{[12]}$ and backward ${ }^{[13]}$ snowballing methods. Both of them include manual and automatic search and selection of suitable studies. The comparison of the number of papers found before and after applying snowballing is presented in Figure 1.

To generate hypotheses, we need to select papers with empirical results. Based on quantitative values provided in each paper, techniques such as meta-analysis ${ }^{[14]}$ can help further to test hypotheses and find confounding factors.

To form new hypotheses, we defined the following criteria for paper selection:

- containing empirical results from conducted experiments;

- comparison of two or more different techniques, methods, of languages; and

- containing all presented values in joules or watts.

During the search process, we excluded duplicated and irrelevant studies. If a paper does not provide the full information about experiments done or misses the exact values, it was also removed from further consideration. Overall, after the second quality assessment, we rejected $44 \%$ of the found papers and left only 189 papers containing empirical results. 
Table 2. Tools for estimation

\begin{tabular}{|c|c|c|}
\hline & Hypothesis & Studies \\
\hline 1 & $\begin{array}{l}\text { There is a significant difference between the prediction of the dynamic es- } \\
\text { timator and real values }\end{array}$ & [15] \\
\hline 2 & $\begin{array}{l}\text { There is a significant difference between the prediction of the Colored Petri } \\
\text { net model and real values }\end{array}$ & [16] \\
\hline 3 & $\begin{array}{l}\text { There is a significant difference between the prediction of the multilinear } \\
\text { regression model and real values }\end{array}$ & [17] \\
\hline 4 & $\begin{array}{l}\text { There is a significant difference between the energy consumption predic- } \\
\text { tion of the linear models and real values }\end{array}$ & [18-20] \\
\hline 5 & $\begin{array}{l}\text { There is a significant difference between the prediction of the instruction- } \\
\text { level estimation model and real values }\end{array}$ & [21-24] \\
\hline 6 & $\begin{array}{l}\text { There is a significant difference between the prediction of hierarchical per- } \\
\text { formance modeling and real values }\end{array}$ & [25] \\
\hline 7 & $\begin{array}{l}\text { There is a significant difference in energy consumption between the pre- } \\
\text { diction of the functional-level estimation model and real values }\end{array}$ & [26] \\
\hline 8 & $\begin{array}{l}\text { There is a significant difference in power consumption between the esti- } \\
\text { mation of a trace-analysis method and real values }\end{array}$ & [27] \\
\hline
\end{tabular}

\section{RESULTS}

In the previous section, we describe the process of obtaining the results of data extraction from primary studies. This section reports and analyzes the findings to answer the stated research questions.

\section{What are the papers that addressed energy consumption in software engineering from 2010 to 2020 ?}

Figure 1 shows the 340 papers found that are related to energy consumption in software development.

For which devices was energy consumption measured in existing studies?

The available studies were divided into three groups considering the devices for which energy consumption was measured:

- mobile devices;

- cloud systems; and

- embedded systems.

What hypotheses we can derive from the studies found?

Out of the studies we found, only 189 papers contain empirical results. We analyzed them and highlighted 78 studies that can form plausible hypotheses. The rest of the papers contain results that can be explained by a direct relationship, for example, the increase of power or energy consumption with higher CPU usage.

Since we are interested in exploring research hypotheses, we further proceeded with our work using the 78 highlighted studies. During the analysis of these studies, we found that the generated hypotheses could be divided into the following groups:

- hypotheses related to the tools for estimating energy consumption (Table 2);

- hypotheses related to the impact of a design choice on the energy consumption (Table 3); and

- hypotheses related to the impact of platform-specific issues on the energy consumption (Table 4).

The first group of hypotheses compares the energy consumption values obtained from an estimation tool with the real ones. The second group describes, how the design choice while developing an application can affect the energy spent by different devices. The third group addresses the relationship between platform-specific 
Table 3. Design choice

\begin{tabular}{|c|c|c|}
\hline & Hypothesis & Studies \\
\hline 1 & $\begin{array}{l}\text { There is a significant difference in energy consumption induced by differ- } \\
\text { ent sorting algorithms }\end{array}$ & {$[28-34]$} \\
\hline 2 & $\begin{array}{l}\text { There is a significant difference in energy consumption between local exe- } \\
\text { cution and offloading }\end{array}$ & [35-38] \\
\hline 3 & $\begin{array}{l}\text { There is a significant difference in energy consumption with and without } \\
\text { cache }\end{array}$ & [39-41] \\
\hline 4 & $\begin{array}{l}\text { There is a significant difference in energy consumption before and after } \\
\text { applying refactoring techniques }\end{array}$ & [42-44] \\
\hline 5 & $\begin{array}{l}\text { There is a significant difference in energy consumption induced by differ- } \\
\text { ent programming languages }\end{array}$ & {$[1,45-50]$} \\
\hline 6 & $\begin{array}{l}\text { There is a significant difference in energy consumption between different } \\
\text { data collection types (and their variants) while performing similar opera- } \\
\text { tions }\end{array}$ & [51,52] \\
\hline 7 & $\begin{array}{l}\text { There is a significant difference in energy consumption between different } \\
\text { deep learning models }\end{array}$ & [53] \\
\hline 8 & $\begin{array}{l}\text { There is a significant difference in energy consumption between different } \\
\text { data mining algorithms }\end{array}$ & [27] \\
\hline 9 & $\begin{array}{l}\text { There is a significant difference in energy consumption between different } \\
\text { machine learning algorithms }\end{array}$ & {$[3,54,55]$} \\
\hline 10 & $\begin{array}{l}\text { There is a significant difference in energy consumption between mobile } \\
\text { applications: native vs. cross-platform/language development }\end{array}$ & {$[50,56]$} \\
\hline 11 & $\begin{array}{l}\text { There is a significant difference in energy consumption between different } \\
\text { file formats on mobile devices }\end{array}$ & {$[57,58]$} \\
\hline 12 & $\begin{array}{l}\text { There is a significant difference in energy consumption between different } \\
\text { encryption algorithms (including hash algorithms) }\end{array}$ & [59-61] \\
\hline 13 & $\begin{array}{l}\text { There is no significant difference in energy consumption between iterative } \\
\text { and recursive functions }\end{array}$ & [57] \\
\hline
\end{tabular}

Table 4. Platform issues

\begin{tabular}{|c|c|c|}
\hline & Hypothesis & Studies \\
\hline 1 & $\begin{array}{l}\text { There is a significant difference in energy consumption induced by differ- } \\
\text { ent offloading schemes }\end{array}$ & {$[38,62-73]$} \\
\hline 2 & $\begin{array}{l}\text { There is a significant difference in power consumption induced by different } \\
\text { system states }\end{array}$ & [74] \\
\hline 3 & $\begin{array}{l}\text { There is a significant difference in energy consumption between different } \\
\text { resource allocation/scheduling techniques (cloud systems) }\end{array}$ & [75-83] \\
\hline 4 & $\begin{array}{l}\text { There is a significant difference in energy consumption between different } \\
\text { resource allocation/scheduling techniques (embedded systems) }\end{array}$ & [84] \\
\hline 5 & $\begin{array}{l}\text { There is a significant difference in energy consumption between different } \\
\text { resource allocation/scheduling techniques (mobile devices) }\end{array}$ & {$[71,85]$} \\
\hline 6 & $\begin{array}{l}\text { There is a significant difference in energy consumption between different } \\
\text { network technologies/standards }\end{array}$ & [86-92] \\
\hline 7 & $\begin{array}{l}\text { There is a significant difference in energy consumption between different } \\
\text { mobile "interface technologies" }\end{array}$ & [93] \\
\hline 8 & $\begin{array}{l}\text { There is a significant difference in energy consumption between different } \\
\text { operating systems on mobile devices }\end{array}$ & [94] \\
\hline
\end{tabular}

issues and energy consumption.

To better understand the structure of the generated hypotheses, we decided to represent them in a mind map (Figure 2). As described above, we have three big categories: design choice, estimation tools, and platform issues. Opposite to each category, we present the general context of available hypotheses.

\section{DISCUSSION}

The presented review aimed to probe the current possible hypotheses that can be further investigated. In the areas of energy consumption of mobile devices, embedded, and cloud systems, 340 papers were considered. Of these papers, 189 studies contained empirical results, and we were able to generate plausible hypotheses only from 78 studies. These studies were divided into three groups named: tools for estimation, design choice, and platform issues. 


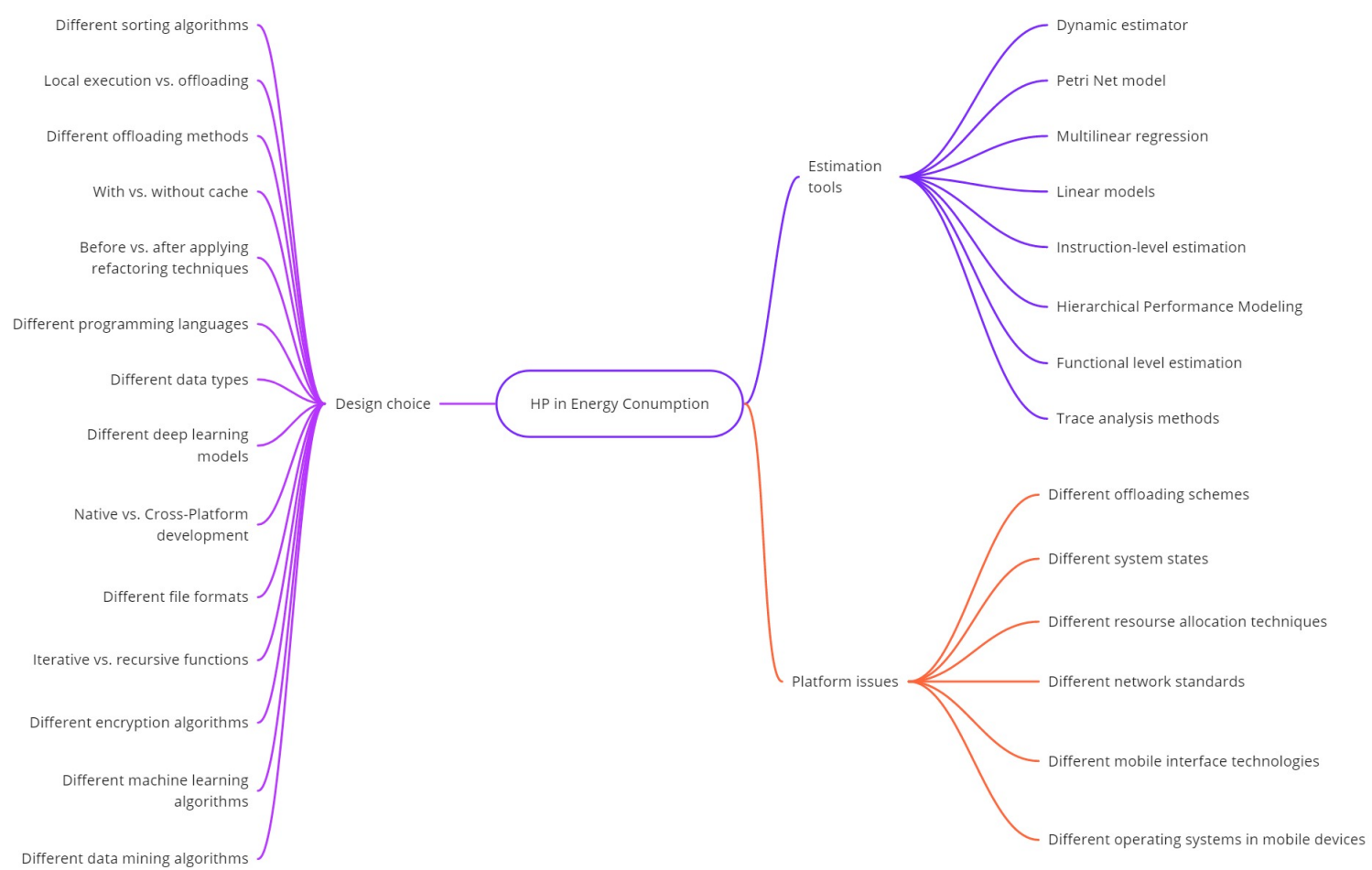

Figure 2. Mind map of hypotheses.

With the first group of hypotheses, the developers can choose the appropriate tools to estimate the energy spent by their application. The second group can help them in making informed decisions about the design choices that would lead to the production of energy-friendly software. The third group helps in detecting the platform characteristics that consume less energy while using them. The second and third groups of hypotheses are mostly under consideration while developing the software.

As shown in Figure 1, the majority of studies found during the search revolved around the energy consumption of embedded systems. Nevertheless, the resulting list of hypotheses revolves more around cloud systems and mobile devices, corresponding to the relevant papers that passed the quality assessment.

In mobile devices, the trend in the last 10 years seems to focus on proposing different offloading schemes (13 papers), a technique that migrates mobile tasks to a cloud infrastructure to reduce the local energy consumption. In a similar vein, the studies found on cloud systems focused on implementing different resource allocation techniques and studying their effect (nine papers). These techniques include VM placement techniques (VM allocation and VM migration), task and resource consolidation and allocation, and many papers focused on the dynamic voltage and frequency scaling (DVFS) task-allocation technique. As for embedded systems, papers seem to mostly address hypotheses from the first group (tools for estimation).

From all of these groups, the hypothesis considering different offloading schemes was the most studied one. The hypotheses related to the different scheduling techniques, network technologies, sorting algorithms, and programming languages also include more studies than the rest. Thus, these topics could be further investigated using different aggregation techniques to derive a general conclusion. 


\section{CONCLUSION}

The review conducted within this project shows the not yet investigated hypotheses that can play an important role in the development of green software. With the help of the presented hypotheses tables, we can see which hypotheses need more attention. In Table 2, we can see that, for most of the hypotheses, we have only one paper. Thus, all groups related to the tools of estimation are lacking papers. This situation makes the choice of suitable tools difficult. On the one hand, it is understandable that there are many solutions for estimation and they vary from one tool or method to another. On the other hand, there is a need for a standard solution for the developers to understand how much energy is spent by their applications ${ }^{[7]}$. Hypotheses with a sufficient number of papers can be further investigated using meta-analytical techniques. Such investigation will statistically prove if one method or tool is more energy-efficient than another one.

Needless to say, our research has some limitations. It is limited to the articles we found using the Google Scholar engine and to the scope of the search set up for the period from 2010 to 2021. It is not guaranteed that we found all relevant papers. Nonetheless, we believe that our findings are important. They define the direction for future research and show questions that are still open.

This research became a step towards understanding how to make software "green". Further, we will consider different meta-analytical techniques that will allow us to consider how the presented hypotheses make a choice in favor of more efficient solutions. The understanding of more efficient solutions can help us to integrate them into industry and reduce the overall consumption of energy.

\section{FUTURE WORK}

As mentioned above, this set of hypotheses can help us to understand the direction for future investigation. From the results shown in the tables, we can understand for which hypotheses we have a sufficient number of papers and which ones can be tested.

As future work, we choose the hypotheses related to the design choices. The understanding of energy efficiency of different algorithms and methods will help us to make software "green". In our next step, we will focus on the energy consumption of different sorting algorithms.

\section{DECLARATIONS}

\section{Acknowledgments}

This research project is carried out under the support of the Russian Science Foundation Grant № 19-19-00623.

\section{Authors' contributions}

Made substantial contributions to conception and design of the study and performed data analysis and interpretation: Hamizi I, Kholmatova Z, Succi G

Performed data acquisition, as well as provided administrative, technical, and material support: Hamizi I, Kholmatova Z, Succi G

\section{Availability of data and materials}

Not applicable.

\section{Financial support and sponsorship}

This research project is carried out under the support of the Russian Science Foundation Grant $\mathrm{N}^{o} 19-19-00623$. 


\section{Conflicts of interest}

All authors declared that there are no conflicts of interest.

\section{Ethical approval and consent to participate}

Not applicable.

\section{Consent for publication}

Not applicable.

\section{Copyright}

(c) The Author(s) 2021.

\section{REFERENCES}

1.سm Oliveira!: , Oliveira[5, Castor】) [“A study on the energy consumption of android app development approaches,” in 2017 IEEE/ACM 14th International Conference on Mining Software Repositories (MSR)!pp. 42घ52, IEEE, 2017.

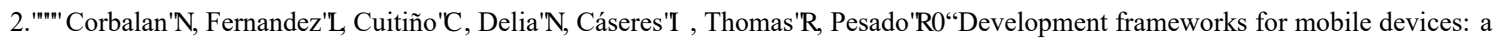
comparative study about energy consumption," in Proceedings of the 5th International Conference on Mobile Software Engineering and Systems $\square$ pp. 191ロ201, 2018.

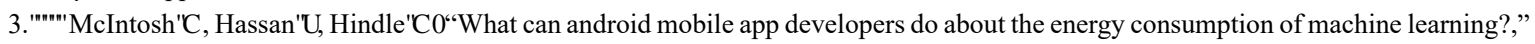
Empirical Software Engineering $\square$ vol. 24, no. 2, pp. 562ロ601, 2019.

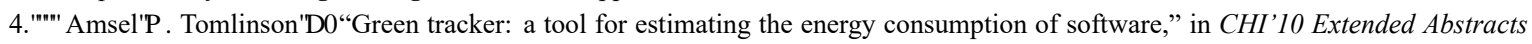
on Human Factors in Computing Systems $\square$ pp. 3337ロ42, 2010.

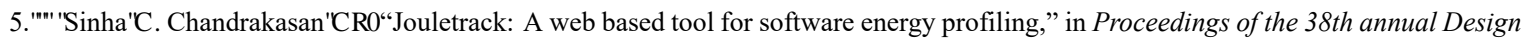
Automation Conference $\llbracket$ pp. 220ロ5, 2001.

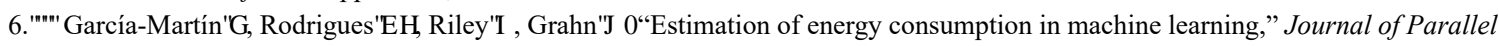
and Distributed Computing $\square$ vol. 134, pp. 75ロ88, 2019.

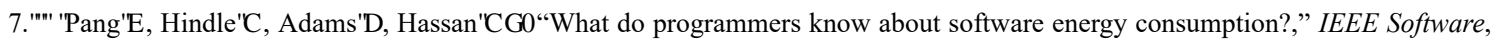
vol. 33 , no. $3 \square$ pp. $83 \square 9,2015$.

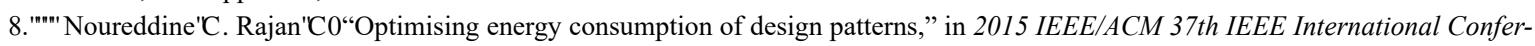
ence on Software Engineering $\square$ vol. 2, pp. 623ロ6, IEEE, 2015.

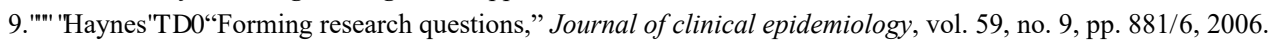

10.ஐ Kitchenham[\% "Procedures for performing systematic reviews," Keele, UK, Keele University, vol. 33, no. 2004, pp. 1-26, 2004.

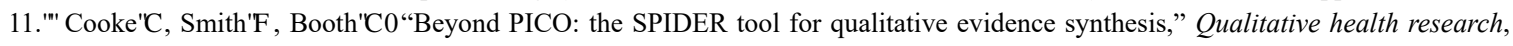
vol. 22 , no. 10 , pp. $1435 \square 43,2012$.

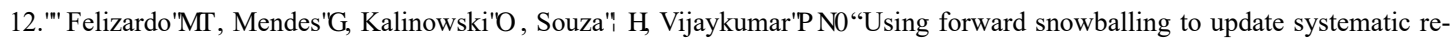
views in software engineering," in Proceedings of the 10th ACM/IEEE International Symposium on Empirical Software Engineering and Measurement, pp. 1ロ6, 2016.

13.凹Wohlin $\llbracket \&$ “Guidelines for snowballing in systematic literature studies and a replication in software engineering," in Proceedings of the 18th international conference on evaluation and assessment in software engineering, pp. 1010, 2014.

14.凹 Weinberg[\&5 “"Toward a clearer definition of confounding," American journal of epidemiology, vol. 137, no. 1, pp. 1 118, 1993.

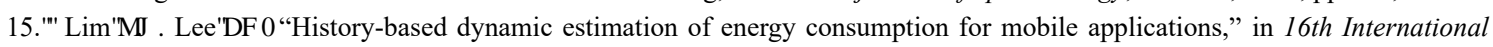
Conference on Advanced Communication Technology, pp. 714ロ8, IEEE, 2014.

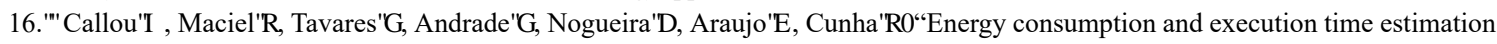
of embedded system applications," Microprocessors and Microsystems, vol. 35, no. 4, pp. 426ロ40, 2011.

17. M. Rodriguez-Martinez, H. Valdivia, J. Seguel, and M. Greer, "Estimating power/energy consumption in database servers," Procedia Computer Science, vol. 6, pp. 112-117, 2011.

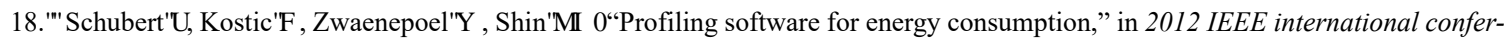
ence on green computing and communications, pp. 515ロ22, IEEE, 2012.

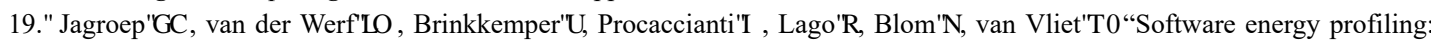
Comparing releases of a software product," in Proceedings of the 38th International Conference on Software Engineering Companion, pp. $523 \square 32,2016$.

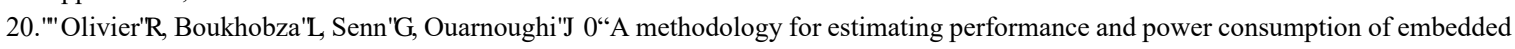
flash file systems," ACM Transactions on Embedded Computing Systems (TECS), vol. 15, no. 4, pp. 1125, 2016.

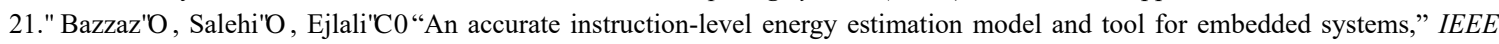
transactions on instrumentation and measurement, vol. 62, no. 7, pp. 1927ロ34, 2013.

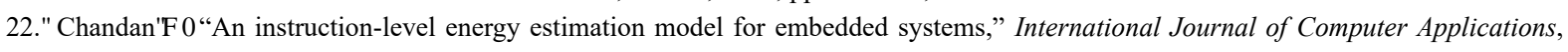
vol. 975 , p. 8887. 


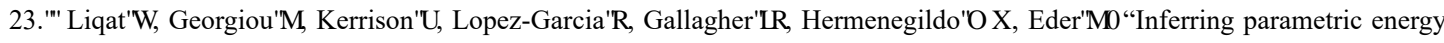
consumption functions at different software levels: Isa vs. 1lvm ir," in International Workshop on Foundational and Practical Aspects of Resource Analysis, pp. 811100, Springer, 2015.

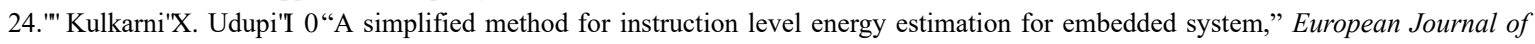
Engineering and Technology Research, vol. 2, no. 5, pp. 56ロ9, 2017.

25. Alsheikhy\\$ , Han[6, Ammar[5 "Delay and power consumption estimation in embedded systems using hierarchical performance modeling," in 2015 IEEE International Symposium on Signal Processing and Information Technology (ISSPIT), pp. 34凹9, IEEE, 2015.

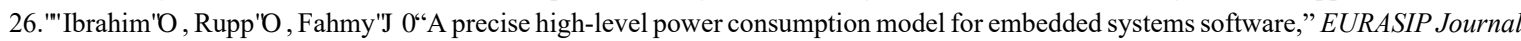
on Embedded Systems, vol. 2011, pp. 1114, 2011.

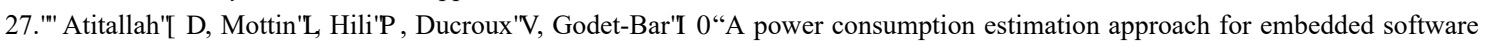
design using trace analysis," in 201541 st Euromicro Conference on Software Engineering and Advanced Applications, pp. 61ロ8, IEEE, 2015.

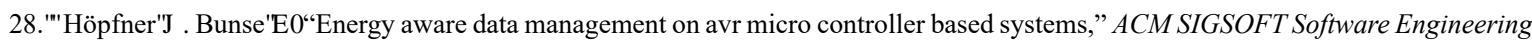
Notes, vol. 35, no. 3, pp. 1卬8, 2010.

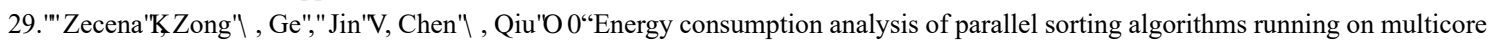
systems," in 2012 International Green Computing Conference (IGCC), pp. 1-6, IEEE, 2012.

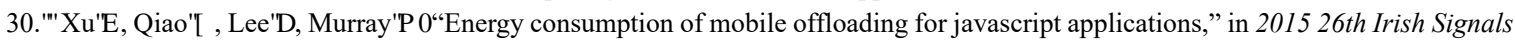
and Systems Conference (ISSC), pp. 1106, IEEE, 2015.

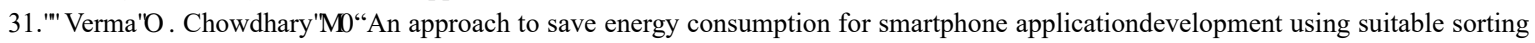
algorithm.," International Journal of Advanced Research in Computer Science, vol. 8, no. 8, 2017.

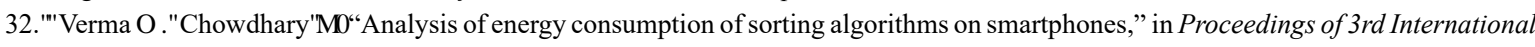
Conference on Internet of Things and Connected Technologies (ICIoTCT), pp. 26ロ7, 2018.

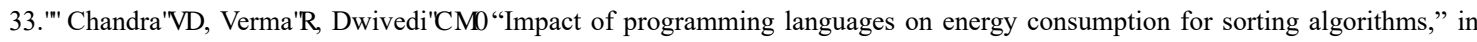
Software Engineering, pp. 930101, Springer, 2019.

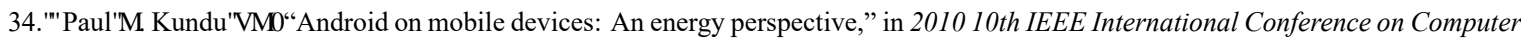
and Information Technology, pp. 242106, IEEE, 2010.

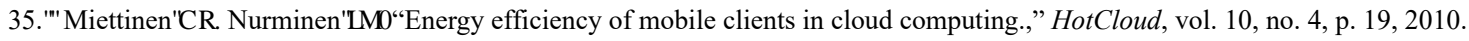

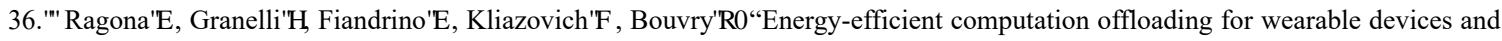
smartphones in mobile cloud computing," in 2015 IEEE Global Communications Conference (GLOBECOM), pp. 1ロ6, IEEE, 2015.

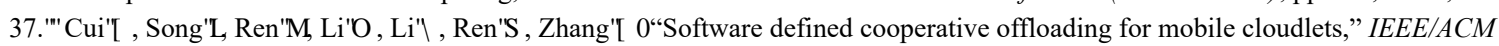
Transactions on Networking, vol. 25, no. 3, pp. 1746匹60, 2017.

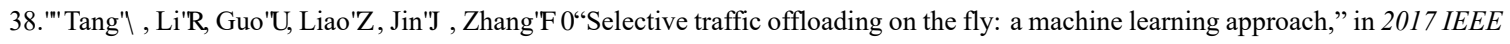
37th International Conference on Distributed Computing Systems (ICDCS), pp. 2386ロ92, IEEE, 2017.

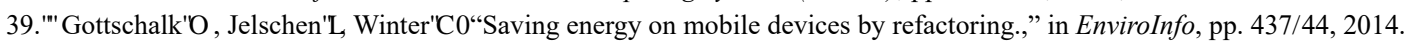

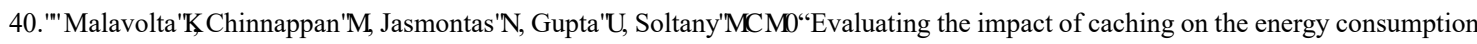
and performance of progressive web apps," in Proceedings of the IEEE/ACM 7th International Conference on Mobile Software Engineering and Systems, pp. 109ロ19, 2020.

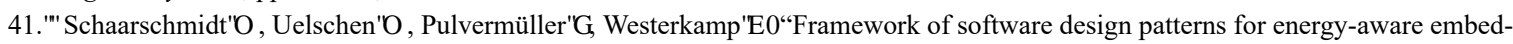
ded systems," 2020.

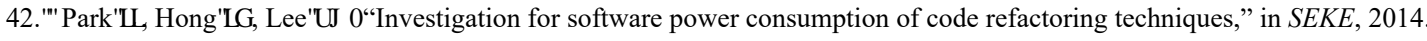

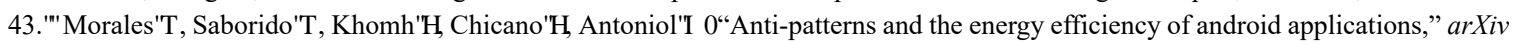
preprint arXiv: 1610.05711, 2016.

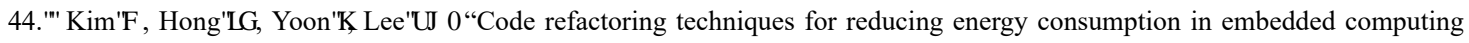
environment," Cluster computing, vol. 21, no. 1, pp. 1079ロ95, 2018.

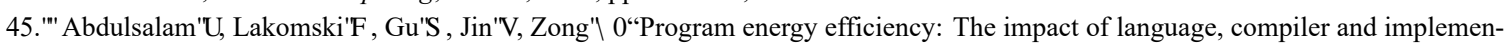
tation choices," in International Green Computing Conference, pp. 116, IEEE, 2014.

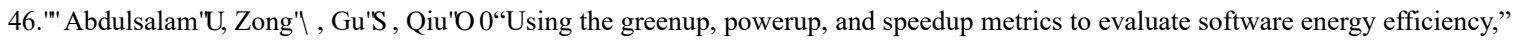
in 2015 Sixth International Green and Sustainable Computing Conference (IGSC), pp. 18, IEEE, 2015.

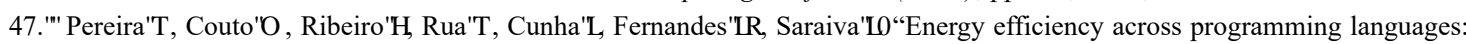
how do energy, time, and memory relate?," in Proceedings of the 10th ACM SIGPLAN International Conference on Software Language Engineering, pp. 256ロ67, 2017.

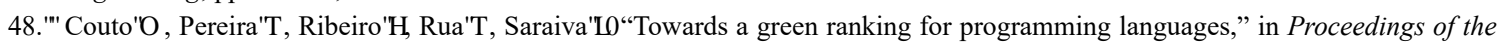
21st Brazilian Symposium on Programming Languages, pp. 1卬8, 2017.

49. $\square$ Chen』; $\square$ Zong $\llbracket \square$ “Android app energy efficiency: The impact of language, runtime, compiler, and implementation," in 2016 IEEE international conferences on big data and cloud computing (BDCloud), social computing and networking (socialcom), sustainable computing and communications (sustaincom)(BDCloud-socialcom-sustaincom), pp. 485ロ92, IEEE, 2016.

50.凹 Oliveira!: , Torres $\llbracket$ : , Castor $\rrbracket$, Ximenes $\llbracket \%+\square$ "Native or web? a preliminary study on the energy consumption of android development models," in 2016 IEEE 23rd International Conference on Software Analysis, Evolution, and Reengineering (SANER), vol. 1, pp. 589ロ93, IEEE, 2016.

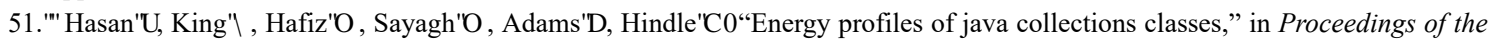


38th International Conference on Software Engineering, pp. 225ロ36, 2016.

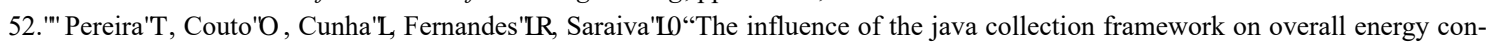
sumption," in 2016 IEEE/ACM 5th International Workshop on Green and Sustainable Software (GREENS), pp. 15ロ21, IEEE, 2016.

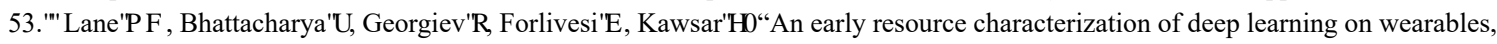
smartphones and internet-of-things devices," in Proceedings of the 2015 international workshop on internet of things towards applications, pp. 7ロ12, 2015.

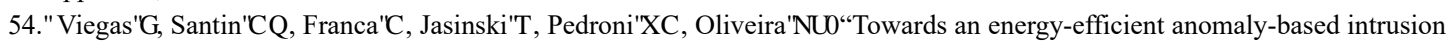
detection engine for embedded systems," IEEE Transactions on Computers, vol. 66, no. 1, pp. 163ロ77, 2016.

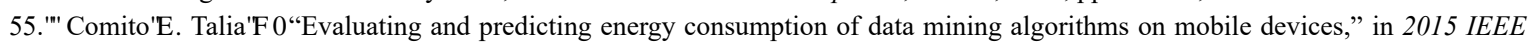
International Conference on Data Science and Advanced Analytics (DSAA), pp. 1ロ8, IEEE, 2015.

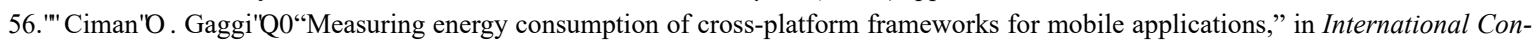
ference on Web Information Systems and Technologies, pp. 331ロ46, Springer, 2014.

57.ஐ Cristea[9, Pattinson[\&, Kor[\$ “Energy consumption of mobile phones," 2015.

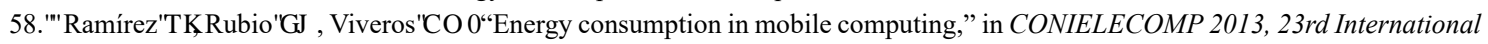
Conference on Electronics, Communications and Computing, pp. 132ロ7, IEEE, 2013.

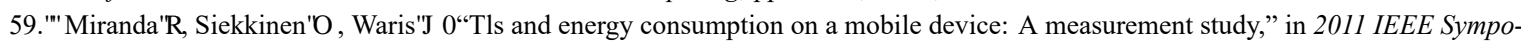
sium on Computers and Communications (ISCC), pp. 98349, IEEE, 2011.

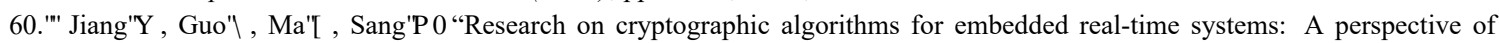
measurement-based analysis," in 2012 IEEE 14th International Conference on High Performance Computing and Communication \& 2012 IEEE 9th International Conference on Embedded Software and Systems, pp. 1495-1501, IEEE, 2012.

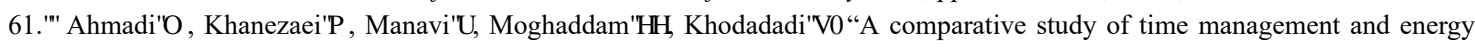
consumption in mobile cloud computing," in 2014 IEEE 5th Control and System Graduate Research Colloquium, pp. 1990203, IEEE, 2014.

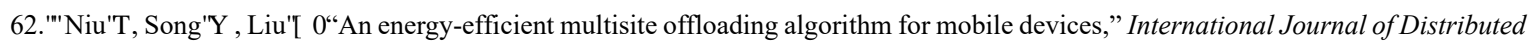
Sensor Networks, vol. 9, no. 3, p. 518518, 2013.

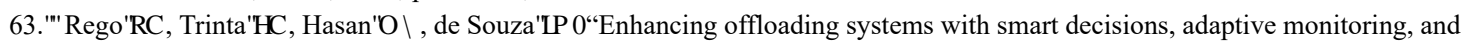
mobility support," Wireless Communications and Mobile Computing, vol. 2019, 2019.

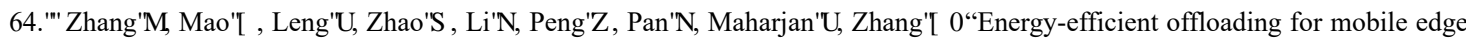
computing in 5g heterogeneous networks," IEEE access, vol. 4, pp. 5896-5907, 2016.

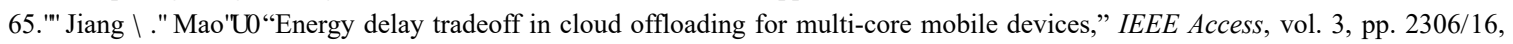
2015.

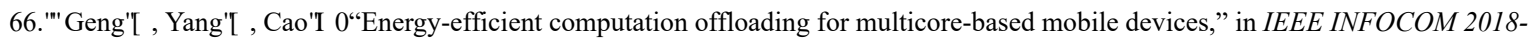
IEEE Conference on Computer Communications, pp. 46ロ54, IEEE, 2018.

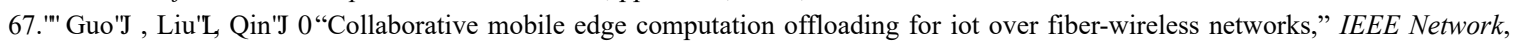
vol. 32, no. 1, pp. 66ロ71, 2018.

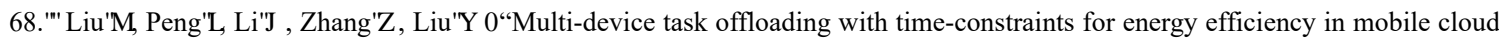
computing," Future Generation Computer Systems, vol. 64, pp. 1114, 2016.

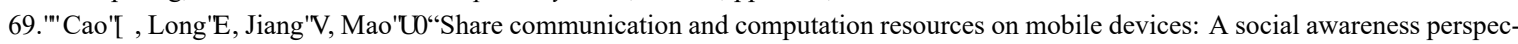
tive," IEEE Wireless Communications, vol. 23, no. 4, pp. 52ロ9, 2016.

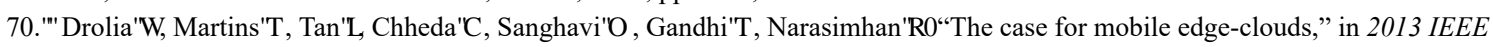
10th International Conference on Ubiquitous Intelligence and Computing and 2013 IEEE 10th International Conference on Autonomic and Trusted Computing, pp. 209ロ15, IEEE, 2013.

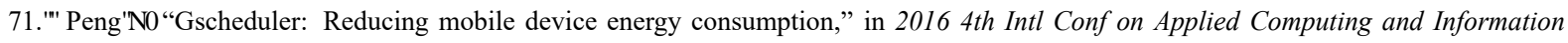
Technology/3rd Intl Conf on Computational Science/Intelligence and Applied Informatics/1st Intl Conf on Big Data, Cloud Computing, Data Science \& Engineering (ACIT-CSII-BCD), pp. 1-6, IEEE, 2016.

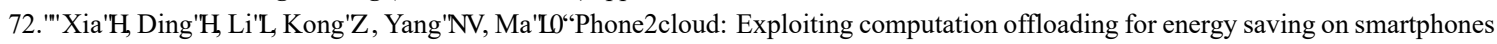
in mobile cloud computing," Information Systems Frontiers, vol. 16, no. 1, pp. 95-111, 2014.

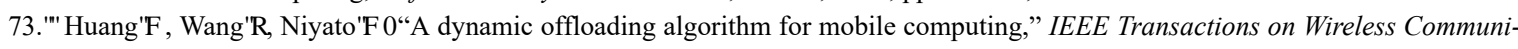
cations, vol. 11, no. 6, pp. 199105, 2012.

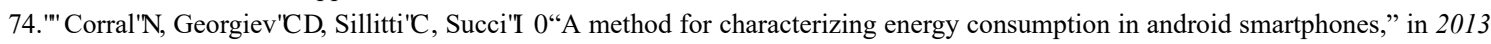
2nd international workshop on green and sustainable software (GREENS), pp. 38匹45, IEEE, 2013.

75.凹 Mishra[6. , Mishra[6, Bharti[6. , Sahoo[\% Puthal[ , Kumar[0 \ "Vm selection using dvfs technique to minimize energy consumption in cloud system," in 2018 International Conference on Information Technology (ICIT), pp. 284凹9, IEEE, 2018.

76.凹Gourisaria[0 . , Patra[6, Khilar[3]“Energy saving task consolidation technique in cloud centers with resource utilization threshold," in Progress in Advanced Computing and Intelligent Engineering, pp. 655ロ66, Springer, 2018.

77. Mishra[6. , Parida[33, Sahoo[6, Sahoo[\% Jena[6. \“Improving energy usage in cloud computing using dvfs,” in Progress in Advanced Computing and Intelligent Engineering, pp. 623ロ32, Springer, 2018.

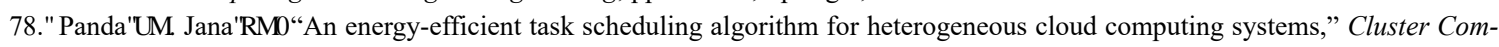
puting, vol. 22, no. 2, pp. 509ロ27, 2019.

79. Ali卬\$, Lu『 , Zhul<, Yul- “An energy efficient algorithm for virtual machine allocation in cloud datacenters," in Conference on 
Advanced Computer Architecture, pp. 61072, Springer, 2016.

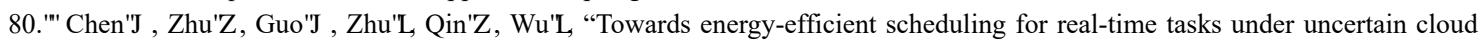
computing environment," Journal of Systems and Software, vol. 99, pp. 20ロ35, 2015.

81.凹 Mishra[6. , Deswal[5, Sahoo[6, Sahoo[\% "Improving energy consumption in cloud," in 2015 Annual IEEE India Conference (INDICON), pp. 1106, IEEE, 2015.

82. Panda[6. \Jana PK. "An efficient energy saving task consolidation algorithm for cloud computing systems," in 2014 International Conference on Parallel, Distributed and Grid Computing, pp. 262-67, IEEE, 2014.

83. Hsu CH, Slagter KD, Chen SC, Chung YC. "Optimizing energy consumption with task consolidation in clouds," Information Sciences, vol. 258, pp. 452-62, 2014.

84. Xu H, Li R, Pan C, Li K. "Minimizing energy consumption with reliability goal on heterogeneous embedded systems," Journal of Parallel and Distributed Computing, vol. 127, pp. 44-57, 2019.

85. Tseng PH, Hsiu PC, Pan CC, Kuo TW. "User-centric energy-efficient scheduling on multi-core mobile devices," in Proceedings of the 51st Annual Design Automation Conference, pp. 1-6, 2014.

86. Bezerra C, De Carvalho A, Borges D, Barbosa N, Pontes J, Tavares E. "Qoe and energy consumption evaluation of adaptive video streaming on mobile device," in 2017 14th IEEE Annual Consumer Communications \& Networking Conference (CCNC), pp. 1-6, IEEE, 2017.

87. Zhao B, Friderikos V. "Balancing transmission and storage cost for reducing energy consumption in mobile devices," in 2013 IEEE 77th Vehicular Technology Conference (VTC Spring), pp. 1-5, IEEE, 2013.

88. Hoffmann J, Neumann S, Holz T. "Mobile malware detection based on energy fingerprints—a dead end?," in International Workshop on Recent Advances in Intrusion Detection, pp. 348-68, Springer, 2013.

89. Barbera MV, Kosta S, Mei A, Stefa J. "To offload or not to offload? the bandwidth and energy costs of mobile cloud computing," in 2013 Proceedings Ieee Infocom, pp. 1285-93, IEEE, 2013.

90. Carroll A, Heiser G. "An analysis of power consumption in a smartphone.," in USENIX annual technical conference, vol. 14, pp. 21-21, Boston, MA, 2010.

91. Lim YS, Chen YC, Nahum EM, Towsley D, Gibbens RJ. "How green is multipath tcp for mobile devices?," in Proceedings of the 4th workshop on All things cellular: operations, applications, \& challenges, pp. 3-8, 2014.

92. Perrucci GP, Fitzek FH, Widmer J. "Survey on energy consumption entities on the smartphone platform," in 2011 IEEE 73rd vehicular technology conference (VTC Spring), pp. 1-6, IEEE, 2011.

93. Herwig V, Fischer R, Braun P. "Assessment of rest and websocket in regards to their energy consumption for mobile applications," in 2015 IEEE 8th International Conference on Intelligent Data Acquisition and Advanced Computing Systems: Technology and Applications (IDAACS), vol. 1, pp. 342-7, IEEE, 2015.

94. Javed A, Shahid MA, Sharif M, Yasmin M. “Energy consumption in mobile phones.," International Journal of Computer Network \& Information Security, vol. 9, no. 12, 2017. 